\title{
Can I Afford to Publish? A Dilemma for African Scholars
}

\author{
Addisu Mekonnen ${ }^{1}$, Colleen Downs ${ }^{2}$, Edu Effiom ${ }^{3}$, Mohamed Kibaja ${ }^{4}$, Michael Lawes ${ }^{2}$, \\ Patrick Omeja ${ }^{5}$, Fanomezana Ratsoavina ${ }^{6}$, Onja Razafindratsima ${ }^{7}$, Dipto Sarkar ${ }^{8}$, Nils \\ Stenseth $^{9}$, and Colin Chapman ${ }^{10}$ \\ ${ }^{1}$ Bahir Dar University \\ ${ }^{2}$ University of KwaZulu-Natal \\ ${ }^{3}$ Cross River State Forestry Commission \\ ${ }^{4}$ University of Dar es Salaam \\ ${ }^{5}$ Makerere University Biological Field Station \\ ${ }^{6}$ Université d'Antananarivo \\ ${ }^{7}$ University of California Berkeley \\ ${ }^{8}$ Carleton University \\ ${ }^{9}$ University of Oslo \\ ${ }^{10}$ Wilson Center
}

September 25, 2021

\begin{abstract}
With open-access publishing authors pay an article processing charge and subsequently their article is freely available online. These charges are beyond the reach of most African academics. Thus, the trend towards open access publishing will shift the business model from a pay-wall model, where access to literature is limited, to a pay-to-publish one, where African scholars cannot afford to publish. We explore the costs of publishing and the ability of African scholars to afford to publish as open access. Three-quarters of the 40 top ecology journals required payment for open-access publishing (average cost $\$ 3,150$ ). Paying such fees is a hardship for African scholars as grant funding is not available and it is not feasible to pay the fees themselves as salaries are low. We encourage funders and publishers to facilitate an equitable publishing model that allows African scholars to make their research available through open-access publishing.
\end{abstract}

\section{Viewpoint}

\section{Can I Afford to Publish? A Dilemma for African Scholars}

Addisu Mekonnen ${ }^{1,2,3^{*}}$, Colleen Downs ${ }^{4}$, Edu O. Effiom ${ }^{5}$, Mohamed Kibaja ${ }^{6}$, Michael J. Lawes ${ }^{4}$, Patrick Omeja $^{7}$, Fanomezana M. Ratsoavina ${ }^{8}$, Onja Razafindratsima ${ }^{9}$, Dipto Sarkar ${ }^{10}$, Nils Chr. Stenseth ${ }^{3,11}$, Colin A. Chapman ${ }^{4,12,13,14}$

${ }^{1}$ Department of Wildlife and Ecotourism Management, Bahir Dar University, Bahir Dar, Ethiopia

${ }^{2}$ Department of Anthropology and Archaeology, University of Calgary, Calgary, Alberta, Canada

${ }^{3}$ Centre for Ecological and Evolutionary Synthesis (CEES), Department of Biosciences, University of Oslo, Oslo, Norway

${ }^{4}$ School of Life Sciences, University of KwaZulu-Natal, Scottsville, Pietermaritzburg, South Africa

${ }^{5}$ Cross River State Forestry Commission, Calabar, Nigeria 
${ }^{6}$ Department of Zoology and Wildlife Conservation, University of Dar Essalam, Dar Essalam, Tanzania

${ }^{7}$ Makerere University Biological Field Station, Fort Portal, Uganda

${ }^{8}$ Zoologie et Biodiversité Animale, Université d'Antananarivo, Antananarivo, Madagascar

${ }^{9}$ University of California, Berkeley, Department of Integrative Biology, Berkeley, USA

${ }^{10}$ Department of Geography and Environmental Studies, Carleton University, Ottawa, Canada

${ }^{11}$ Department of Zoological Sciences, Addis Ababa University, Addis Ababa, Ethiopia

${ }^{12}$ Wilson Center,1300 Pennsylvania Avenue NW, Washington, DC, USA

${ }^{13}$ Department of Anthropology, The George Washington University, Washington DC, USA

${ }^{14}$ Shaanxi Key Laboratory for Animal Conservation, Northwest University, Xi'an, China

Email: Addisu Mekonnen - addisumekonnen@gmail.com, Colleen Downs - Downs@ukzn.ac.za, Edu O. Effiom - edu.efiom@gmail.com, Mohamed Kibaja - mkibaja@gmail.com, Michael J. Lawes - MichaelLawes62@gmail.com, Patrick Omeja - Omejap@yahoo.com, Fanomezana M. Ratsoavina - fanomezanarts@gmail.com, Onja Razafindratsima - onja@berkeley.edu, Dipto Sarkar - dipto.sarkar@carleton.ca, Nils Chr. Stenseth - n.c.stenseth@mn.uio.no, Colin A. Chapman - colin.chapman.research@gmail.com

Running title: Can I afford to Publish

\section{AUTHORSHIP STATEMENT}

$\mathrm{AM}$ and $\mathrm{CAC}$ conceived of the project and wrote the first draft. All authors contributed data, helped with the writing, and approved the final draft

\section{DATA STATEMENT}

All data is open access and is available in the supplementary data. The data will be publicly available in Dryad and the data DOI will be included at the end of the article.

\section{KEYWORDS}

Open access publishing, pay-wall, pay to play, scientific publishing, scientific journals

Manuscript details

Words in Abstract $=146$

Words in Main text $=1993$

Number of References $=22$

Number of Figures $=1$

Number of Table $=0$

\section{Abstract}

With open-access publishing authors pay an article processing charge and subsequently their article is freely available online. These charges are beyond the reach of most African academics. Thus, the trend towards open access publishing will shift the business model from a pay-wall model, where access to literature is limited, to a pay-to-publish one, where African scholars cannot afford to publish. We explore the costs of publishing and the ability of African scholars to afford to publish as open access. Three-quarters of the 40 top ecology journals required payment for open-access publishing (average cost $\$ 3,150$ ). Paying such fees is a hardship for African scholars as grant funding is not available and it is not feasible to pay the fees themselves as salaries are low. We encourage funders and publishers to facilitate an equitable publishing model that allows African scholars to make their research available through open-access publishing. 
Humanity is facing unprecedented environmental challenges, and nowhere will these challenges be greater than in Africa. Over the next century, Africa's population is projected to quadruple (UN 2015), the impact of climate change will be severe (Niang et al. 2014), and environmental conflict is projected to rise sharply (Laurance et al. 2014). It is widely recognized that grappling with these challenges will require substantial investment in the continent's research capacity (Atickem et al. 2019). Yet, African scholars are disadvantaged by their inability to pay to access scientific information and pay to publish their research in the best journals. Most African universities cannot afford institutional journal fees; thus, their faculty have limited access to the latest published research. Such disadvantages have been recognized for some time (Solomon \& Björk 2012a; Björk 2017) and strategies to mitigate them have been put in place. Governments, funders, and publishers have responded with strategies that facilitate better access to literature. For example, Research4Life, working with WHO, FAO, UNEP, and 180 international publishers, provides institutions in low-and middle-income countries with online access to 111,255 books and 28,920 journals. But the publishing world is rapidly changing, and the academic community must adapt.

One way the academic landscape is changing deals with open access. The push to open access publishing began in 2000 (Solomon \& Björk 2016) and is widely accepted as a way of providing access for everyone to journal articles. This is a business model where authors or their institutions pay article processing charges to make their articles freely available online. Currently, these processing charges are beyond the reach of most African academics and their institutions. This is a concern as the number of open access publications funded by article processing charges is increasing exponentially (Solomon \& Björk 2016). Open access is set to increase as European science funders and international foundations launched Plan S 20, which prohibits researchers who receive their funding from publishing in non-open access journals (Else 2018; Rabesandratana 2018; Else 2021). Additionally, open access publishing in ecology will increase because it confers a citation advantage (Tanget al. 2017). As researchers are increasingly evaluated for promotion and grants by metrics (Chapman et al. 2019; Chapmanet al. In Press), there is considerable pressure to pay article processing charges. However, open access is expensive, even by wealthy country standards. For most African scholars, moving to open access publishing is not within reach. Thus, for African scholars the move to open access publishing may shift the business model from a pay-wall model, where access to literature is difficult, to a pay-to-publish model, where it is difficult to have research published (Green 2019). As open access publishing becomes the norm, it will be increasingly difficult for African scholars to fully engage in the scientific process.

In this commentary, we first examine the premise that publishing in high-impact journals is costly. We then review what steps journals have taken to accommodate low-income country authors. Next, we explore the costs of publishing in the top-ranked ecology journals. We provide information on the availability of research funds from our home countries, illustrating the ability of African researchers to pay article processing charges from in-country sources, the salaries of professors at universities in Africa, illustrating the ability of individuals to pay, and the cost of student tuition and research, showing the tradeoff African scientists face between publishing and training.

\section{OPEN ACCESS PUBLISHING IN ECOLOGY}

Do journals with higher impact metrics charge more to publish open access articles? In 2021 we reviewed the article processing charges of all 169 ecology journals considered by Journal Citation Reports (Supplementary Table 1). In this set of journals, $74.0 \%$ provided both open access and pay-wall publishing options (hybrid journals), $22.4 \%$ were open access only, and $4.1 \%$ publish behind a pay-wall only. The average fee to publish open access was US $\$ 2606$ for all journals and US $\$ 1317$ for those that were open access only. As expected, journals with higher impact factors had higher article processing charges $(\mathrm{r}=0.612, \mathrm{P}<0.001$; Figure 1$)$.

We evaluated open access publishing for the top-ranked 40 ecology journals listed in Journal Citation Reports. For each journal, we reviewed online information on open access, their article processing charges, and waivers for low-income countries. In many instances, it was unclear when and how article processing charges are levied; thus, we wrote to all editors for clarification. It became apparent that publishers granted the journal and the editors flexibility in how article processing charges were levied, so different journals associated with the same large publishers have different policies. This allows journals to respond to the research community 
they serve in an adaptable manner, which we view as a positive approach.

Two of the 40 journals were fully open access and for each of these journals there was no waiver option available for African scholars (Supplementary Data Table 2). Two of the journals were invitation only and were not considered further. Two journals did not have the open access option. Excluding the two journals that were invitation only $(\mathrm{n}=38)$, most $(24,63.2 \%)$ were hybrid journals that did not offer waivers for open access publishing, but it was possible to publish for free under the subscription model with the article being available behind a paywall. Nine journals $(23.7 \%)$ provided open access waivers for African scholars. Four journals $(10.5 \%)$ did not offer a waiver for either open access or the subscription model, requiring a fee to be paid in both cases. One journal did not have a waiver for open access but provided a waiver for paying under the subscription model.

For those 40 journals with article processing charges, the average cost was US $\$ 3,150$. Journal websites referred readers to Research4Life to determine if the author's country was eligible for a waiver. However, Research4Life indicated that if an author from a low-income country had co-authors from high-income countries, they are ineligible for a waiver. Upon inquiry with editors, this requirement does not seem to be enforced. Only one journal levied charges if there were co-authors from high-income countries. If publishing fees are discounted only when all authors are African, it puts the African scholar in the inappropriate position of relying on international collaborators to pay to publish the research they lead.

Only $7.9 \%$ of journals asked low-income scholars to pay to publish. However, of those that were not invitation only and offered open access, three-quarters of journals ask for payment for publishing open-access research.

\section{OPEN ACCESS PUBLISHING FOR AFRICAN RESEARCHERS}

Paying article processing fees of approximately $\$ 3000$ is a hardship, as most African countries do not have grants for publication costs. There are no national grant funds available in Ethiopia, Madagascar, or Uganda to pay publication related expenses. In Nigeria the Tertiary Education Trust Fund provides supported; however, these grants are competitive and allow only $\$ 300$ towards publishing. South Africa is not considered a low-income country and is not eligible for waivers through groups such as Research4Life. South Africa's National Research Foundation does support publication costs and some universities offer internal support to cover page charges.

Only $10 \%$ of researchers in ecology, botany, and zoology in North America and Europe always or often have access to funds for article processing fees (Cookson 2012). Thus, researchers often personally pay the fees to publish. It is simply not feasible for African scholars to pay the fees as salaries are low (the monthly starting salary - Uganda US $\$ 2,300$, Tanzania US\$2027, South Africa US\$2176, Madagascar US\$531, Ethiopia US\$365).

For African scholars, grant money is very difficult to obtain. Using grant money to pay article processing charges of around $\$ 3000$ would mean foregoing research or student support. This would be a shame as grant money can go a long way to helping graduate training. Considering the six African countries represented by the co-authors, the average annual tuition costs for a Masters student in ecology is only $\$ 1,086$ US (\$936 excluding South Africa; Supplementary Table 3). Similarly, to support annual tuition, student living stipend, and the research costs for a Master student is $\$ 5,327$ (\$3,638 excluding South Africa). In contrast, the average cost of annual graduate tuition in the USA is $\$ 12,171$ for public institutions and US $\$ 25,929$ for private institutions. The average costs of room and board, books and supplies, and other expenses are also high, around $\$ 14,999$ (Ginder et al.2018). So, the funds that could be allocated to pay article processing charges could go a long way to supporting training in Africa, but not in high income countries, like the USA.

Open access models, where authors pay to publish, increase the advantages of those with resources over those without, promoting inequality (Burgman et al. 2019). This not only pertains to the African context but also to equality within high-income countries; thus, many researchers in high-income countries also struggle to afford to publish. This has led to creative solutions being enacted, such as institutional agreements with publishers to cover or discount article processing charges to their members, publishers promoting funders 
that will cover charges, and granting agencies allowing researchers to include funds to publishing in grants (Tennant et al. 2016). However, these solutions primarily apply to researchers at participating institutions in high-income countries, or individuals who can obtain grants, and in general, they do not apply to African researchers.

There are five stakeholders in open access publication; researchers, universities, foundations, governments, and publishers. As outlined, African researchers and their universities are unlikely to be able to pay article processing charges. It seems unlikely that publishers will change practices that decrease their profit margins as it would run counter to past actions and would not meet stockholder approval. We feel foundations can play a significant role, but likely in targeted research areas or regions. We do not feel that direct foreign government aid is the answer because it often becomes highly bureaucratic, comes with strings attached, and will ebb and flow with changing foreign government administrations. We suggest the solution can come from within the research community. Honest sustained collaborations among African and international researchers will lead to higher quality, longer-term research, and training programs. Such initiatives will in turn lead to successful grant applications. The article processing charges for collaborative research can then be covered by collaborative grants and by institutional agreements in the high-income countries. Thus, the best route to a more equitable future for African researchers with respect to the growth of open access publishing involves international scholars, universities, and granting agencies identifying and implementing processes that facilitate collaboration with African scientists.

\section{CONCLUDING REMARKS}

There has been a rapid shift to open-access publishing and there is every indication that this trend will grow. On the one hand, this is a very positive development for African scholars because with reliable internet, it is possible to keep up-to-date on international research. Conversely, African scholars currently cannot afford to publish in the best journals. We are encouraged to see deliberations on how to make the open-access business model more globally equitable (Solomon \& Björk 2012b, a; Green 2019; Björk 2021). Academics should keep in mind that journals are, for the most part, for-profit businesses with profit margins reaching as high as $40 \%$ (Buranyi 2017). In fact, in 2017 the global revenues from scientific publishing were estimated to be US $\$ 24$ billion, and in 2010 the profit margins were higher than Apple, Google, or Amazon (Buranyi 2017). However, publication charges account for a tiny fraction of the global research and development budget (Else 2018), thus exploring creative ways to maintain equity and diversity in research publishing should be encouraged.

Having research articles available through open access publishing will advance African science and we applaud efforts of funders and publishers who are promoting the accessibility of research to all and creating a more equitable publishing realm. Strategies to make research truly open access should be explored (Beall 2013). Such advances will promote African research and training and will be needed if we are to grapple with the environmental challenges that Africa will to face in the coming years.

\section{DATA STATEMENT}

All data is available in the supplementary data. The data will be publically available in Dryad and the data DOI will be included at the end of the article.

\section{ACKNOWLEDGEMENTS}

CC was supported by the Wilson Center while working on this project. CTD was supported by the National Research Foundation (ZA, Grant 98404). We thank Claire Hemingway for helpful ideas and comment on this project and Adams Chaskda, Director of the A.P. Leventis Ornithological Research Institute (APLORI), University of Jos and Amera Moges from Bahir Dar University for helping us obtain data on the cost of supporting students. We also thank Jonah Ratsimbazafy and Zafimahery Rakotomalala from the University of Antananarivo for helpful discussion about faculty salaries at research institutions in Madagascar.

\section{AUTHORSHIP STATEMENT}

$\mathrm{AM}$ and $\mathrm{CAC}$ conceived of the project and wrote the first draft. All authors contributed data and helped 
with the writing.

\section{PEER REVIEW}

The peer review history of this article is available at To Be Provided Later

\section{ORCID}

Addisu Mekonnen - 0000-0001-8403-1071, Colleen Downs - 0000-0001-8334-1510, Mohamed Kibaja - 00000002-9437-7380, Michael J. Lawes - 0000-0002-2381-6147, Fanomezana M. Ratsoavina - 0000-0003-1661-1669, Onja Razafindratsima - 0000-0003-1655-6647, Dipto Sarkar - 0000-0003-2254-049X, Nils Chr. Stenseth - 00000002-1591-5399, Colin A. Chapman - 0000-0002-8827-8140

\section{REFERENCES}

Atickem, A., Stenseth, N.C., Fashing, P.J., Nguyen, N., Chapman, C.A., Bekele, A. et al. (2019). Build science in Africa. Nature, 570, 297-300.

Beall, J. (2013). The open-access movement is not really about open access. tripleC: Communication, Capitalism 83 Critique. Open Access Journal for a Global Sustainable Information Society, 11, 589-597.

Björk, B.-C. (2017). Open access to scientific articles: a review of benefits and challenges. Internal and emergency medicine , 12, 247-253.

Björk, B.-C. (2021). Why is access to the scholarly journal literature so expensive? portal: Libraries and the Academy , 21, 177-192.

Buranyi, S. (2017). Is the staggeringly profitable buisness of scientific publishing bad for science? In: The Guardian .

Burgman, M., Esler, K., Akcakaya, R., McCarthy, M., Rondinini, C., Main, E. et al. (2019). Open access and academic imperialism.

Chapman, C.A., Bicca-Marques, J.C., Calvignac-Spencer, S., Fan, P., Fashing, P.J., Gogarten, J. et al. (2019). Games academics play and their consequences: How authorship, h-index, and journal impact factors are shaping the future of academia. Proceedings of the Royal Society B: Biological Sciences .

Chapman, C.A., Hemingway, C.A., Sarkar, D., Gogarten, J.F. \& Stenseth, N.C. (In Press). Altmetric scores in conservation science have gender and regional biases. Conservation $\mathcal{E}$ Society .

Cookson, R. (2012). Ecology, botany and zoology researchers not keen to pay open access publication charges, and have limited ability to do so.Editors' Bulletin , 8, 11-23.

Else, H. (2018). Radical plan to end paywalls. Nature , 561, 17-18.

Else, H. (2021). A guide to Plan S: the open-access initiative shaking up science publishing. Nature .

Ginder, S.A., Kelly-Reid, J.E. \& Mann, F.B. (2018). Postsecondary Institutions and Cost of Attendance in 2017-18; Degrees and Other Awards Conferred, 2016-17; and 12-Month Enrollment, 2016-17: First Look (Provisional Data) (NCES 2018-060rev). U.S. Department of Education. Washington, DC: National Center for Education Statistics. Retrieved [August 18, 2021] from http://nces.ed.gov/pubsearch.

Green, T. (2019). Is open access affordable? Why current models do not work and why we need internet-era transformation of scholarly communications. Learned Publishing, 32, 13-25.

Laurance, W.F., Clements, G.R., Sloan, S., O'connell, C.S., Mueller, N.D., Goosem, M. et al. (2014). A global strategy for road building. Nature, 513, 229-232.

Niang, I., Ruppel, O.C., Abdrabo, M.A., Essel, A., Lennard, C., Padgham, J. et al. (2014). Chapter 22 Africa. In: Climate Change 2014: Impacts, Adaptation, and Vulnerability. Part B: Regional Aspects. 
Contribution of Working Group II to the Fifth Assessment Report of the Intergovernmental Panel on Climate Change . Cambridge University Press, Cambridge, United Kingdom and New York, NY, USA.

Rabesandratana, T. (2018). European funders detail their open-access plan. American Association for the Advancement of Science.

Solomon, D. \& Bjork, B.-C. (2016). Article processing charges for open access publication - the situation for research intensive universities in the USA and Canada. PeerJ , 4, e2264.

Solomon, D.J. \& Bjork, B.C. (2012a). Publication fees in open access publishing: Sources of funding and factors influencing choice of journal. Journal of the American Society for Information Science and Technology , 63, 98-107.

Solomon, D.J. \& Bjork, B.C. (2012b). A study of open access journals using article processing charges. Journal of the American Society for Information Science and Technology , 63, 1485-1495.

Tang, M., Bever, J.D. \& Yu, F.H. (2017). Open access increases citations of papers in ecology. Ecosphere, 8, e01887.

Tennant, J.P., Waldner, F., Jacques, D.C., Masuzzo, P., Collister, L.B. \& Hartgerink, C.H. (2016). The academic, economic and societal impacts of Open Access: an evidence-based review. F1000Research , 5.

UN (2015). World population prospects: The 2015 revision, key finding and advance tables. In: $E S A / P / W P .241$. United Nations Department of Economic and Social Affairs.

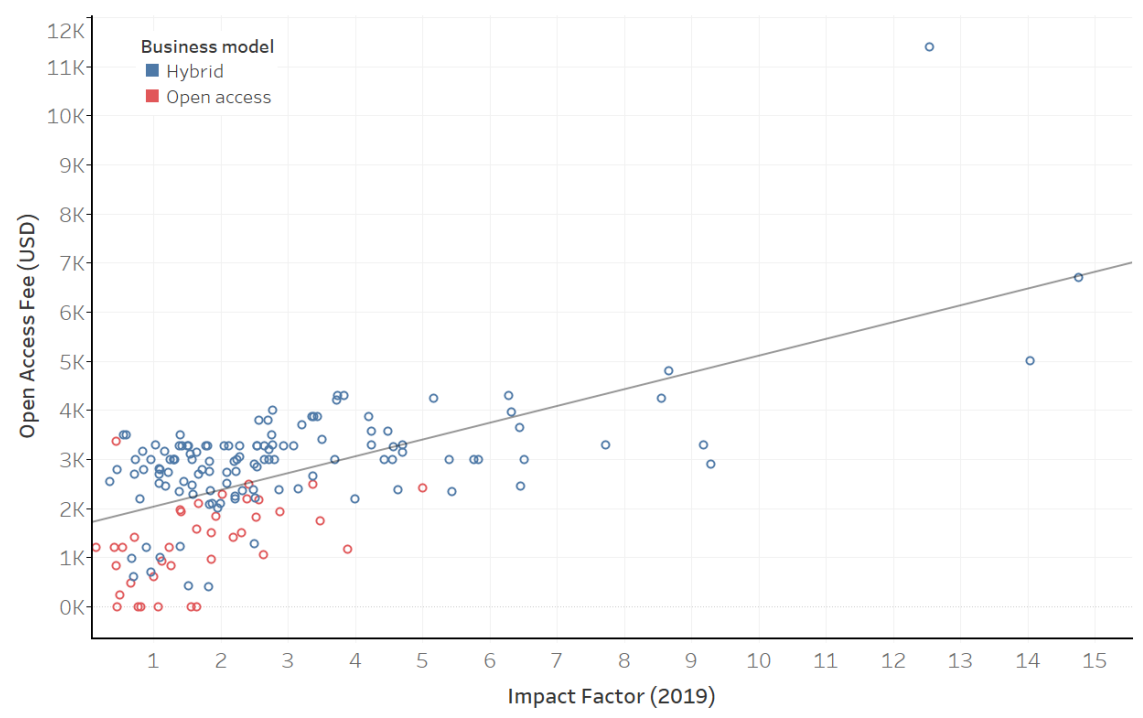

\section{Figure 1:}

The relationship between the Open Access Fees (article processing charges) of all 169 ecology journals considered by the Journal Citation Reports from ISI Web of Knowledge in the ecology category and the impact factor of the journal $(\mathrm{r}=0.612, \mathrm{P}<0.001)$. 